\title{
Bronchoalveolar Lavage Studies in Uveitis Patients without Radiological Intrathoracic Involvement of Sarcoidosis
}

\author{
Mineharu Sugimoto, Hironori NAKASHIMA, Masayuki ANDO, Hirotsugu KOHROGi \\ and Shukuro ARAKI
}

\begin{abstract}
In the present study, we investigated thirty uveitis patients who had a possible diagnosis of ocular sarcoidosis, no respiratory symptoms, and normal chest $\mathbf{X}$-rays, in order to determine whether bronchoalveolar lavage was useful for establishing a diagnosis of subclinical pulmonary involvement of sarcoidosis. Sixteen of 30 uveitis patients showed bronchoalveolar lymphocytosis $(39 \pm 11 \%)$ as compared to normal controls $(14 \pm 3 \%)$. Ten of these 16 patients were associated with significantly increased proportions of CD3 + cells with elevated CD4 + /CD8 + ratios $(P<0.01)$. These data were consistent with those of patients with active pulmonary sarcoidosis (stage 1 and 2) except for total cell count in lavage fluid, but different from those of patients with hypersensitivity pneumonitis. Transbronchial lung biopsy showed noncaseating epithelioid cell granuloma in 4 of 10 uveitis patients with bronchoalveolar T-lymphocytosis and increased CD4 + /CD8 + ratios. Immunohistochemical studies of biopsied lung tissues showed many CD3 + cells and CD4 + cells with very few CD8 + cells in the granuloma. These results suggest that T-lymphocytosis with elevated CD4 + /CD8 + ratios in bronchoalveolar lavage fluid could be a good marker in predicting the pulmonary involvement of sarcoidosis in patients with suspected ocular sarcoidosis and normal chest $\mathbf{X}$-rays.
\end{abstract}

Key words: Uveitis, Normal chest X-rays, Bronchoalveolar lavage, Sarcoidosis

Sarcoidosis is a systemic disease of unknown etiology which is characterized by the presence of noncaseating epithelioid cell granuloma. It is well known that granulomatous uveitis is a major ocular complication of sarcoidosis (1). If uveitis patients have abnormal chest X-rays such as bilateral hilar lymphadenopathy (BHL) and/or pulmonary infiltrates, a diagnosis of sarcoidosis could be made easily. In uveitis patients with normal chest X-rays, however, some other evidences should be sought to establish a diagnosis of sarcoidosis. Recently, by using bronchoalveolar lavage (BAL) technique, subclinical pulmonary involvements have been demonstrated in patients with extrathoracic sarcoidosis (2), patients with Crohn's disease (3), patients with rheumatoid arthritis (4), and patients with HTLV-I-associated myelopathy (5). In this context, the present study was designed to determine whether BAL study was useful for establishing a diagnosis of pulmonary involvement in uveitis patients without radiological intrathoracic involvement of sarcoidosis.

\section{MATERIALS AND METHODS}

Subjects: Study populations consisted of 30 uveitis patients with a possible diagnosis of ocular sarcoidosis and with normal chest X-rays (7 males, 23 females, mean age 35 years, range 15 to 63 years), who were introduced to the sarcoidosis clinic from the Department of Ophthalmology in Kumamoto

From The First Department of Internal Medicine, Kumamoto University Medical School Received for publication July 1, 1988.

Reprint requests to: Mineharu Sugimoto, MD, The First Department of Internal Medicine, Kumamoto University Medical School, 1-1-1 Honjo, Kumamoto 860 Japan 
University Hospital. All of these uveitis patients underwent the clinical and laboratory examinations to differentiate other disorders showing similar ophthalmologic abnormalities such as tuberculosis, Bechet disease, or collagen vascular diseases. None of the patients showed the evidence of these disorders. The following subjects served as controls; Eleven patients with histologically-proven pulmonary sarcoidosis (6 males, 5 females, mean age 34.8 years, range 21 to 63 years, stage $1 ; 4$ patients, stage 2; 7 patients), 9 patients with summer-type hypersensitivity pneumonitis induced by Trichosporon cutaneum ( 2 males, 7 females, mean age 44.8 years, range 30 to 63 years), and 10 nonsmoking male healthy volunteers (mean age 26.5 years, range 25 to 31 years). There were 4 smokers in patients with uveitis, 2 in patients with pulmonary sarcoidosis, and 1 in patients with hypersensitivity pneumonitis.

Bronchoalveolar lavage: After obtaining informed consent, BAL was performed as described previously (6). Briefly, a flexible fiberoptic bronchoscope was advanced to the wedge position in the right anterior basal bronchus and $150 \mathrm{ml}$ of sterile saline was instilled in three aliquots. The fluid was retrieved by gentle suction using a sterile syringe and passed through 2 sheets of gauze to remove mucus. After centrifugation at $400 \mathrm{~g}$ for $10 \mathrm{~min}$ at $4^{\circ} \mathrm{C}$, the sedimented cells were washed twice with Hanks' balanced salt solution and total cells were counted by a hemocytometer. An aliquot of cell suspensions was smeared and stained with Diff Quick for differential cell counts.

Determination of T-cell subsets: T-cell subsets in peripheral blood and BAL fluids were determined by flow cytometry using FITC-conjugated murine monoclonal antibodies (OKT3, OKT4, OKT8, Ortho Diagnostic Systems, NJ) as reported previously (7). T-cell subsets in the lung tissues obtained by transbronchial lung biopsy were stained immunohistochemically using immunoperoxidase stain kit, Histoset (OKT3, OKT4, OKT8, Ortho Diagnostic Systems, NJ).

Measurement of serum ACE levels: Colorimetric method of Kasahara and Ashihara was employed to determine serum ACE levels, using phydroxybenzyl-glycil-histidyl-leucine as substrate (8).

Determination of soluble interleukin-2 receptor
(IL-2R): Serum levels of soluble IL-2R were measured by the enzyme immunometric assay using IL-2R assay kit (Cellfree, T-cell Sciences, Inc., MA) (9). Briefly, serum and IL-2R standards were incubated for $90 \mathrm{~min}$ at room temperature with the plastic beads coated with murine monoclonal antibody directed against one epitope on the IL-2R molecule and with the horseradish-labeled murine monoclonal antibody directed against a second epitope on the same molecule. After washing to remove unbound anti-IL-2R antibodies, the beads were incubated for $30 \mathrm{~min}$ with enzyme substrate solution (o-phenylenediamine) containing hydrogen peroxide. The reaction was terminated by the addition of $1 \mathrm{~N}$-sulfric acid. The absorbance at $492 \mathrm{~nm}$ was measured by a spectrophotometer. The values were shown as units per $\mathrm{ml}(\mathrm{U} / \mathrm{ml})$.

Statistical method: All data were shown as mean \pm standard deviation (SD). Statistical analysis was performed by unpaired $t$ test and $P$ values less than 0.05 were considered significant.

\section{RESULTS}

Characteristics of bronchoalveolar lavage cells: There were no significant differences in recovery ratios and total cell counts between uveitis patients and normal controls (recovery ratio; $45 \pm 16$ vs 47 $\pm 11 \%$, total cell counts; $11 \pm 9$ vs $9 \pm 3 \times 10^{4}$ cells/ml, respectively). As shown in Figure 1, a proportion of lymphocytes in BAL fluid was not increased in 14 of 30 uveitis patients as compared to normal controls (less than 20\%). However, other 16 patients with uveitis showed BAL lymphocytosis (39 \pm 11 ), though total cell counts were not increased

Table 1. T-cell subsets in bronchoalveolar lavage fluid

\begin{tabular}{lccccc}
\hline & $\begin{array}{c}\text { Lymphocytes } \\
(\%)\end{array}$ & \multicolumn{4}{c}{ T-cell subsets (\%) } \\
\cline { 3 - 6 } & & CD3+ & CD4+ & CD8 + & CD4+/CD8 + \\
\hline Uveitis $(n=10)^{\star}$ & $40 \pm 16$ & $77 \pm 5$ & $67 \pm 8$ & $16 \pm 5$ & $5.1 \pm 2.8$ \\
$\begin{array}{l}\text { Pulmonary } \\
\text { Sarcoidosis }(n=11)\end{array}$ & $45 \pm 13$ & $82 \pm 8$ & $71 \pm 7$ & $12 \pm 7$ & $7.9 \pm 4.0$ \\
$\begin{array}{l}\text { Hypersensitivity } \\
\text { pneumonitis }(n=9)\end{array}$ & $75 \pm 15$ & $84 \pm 12$ & $28 \pm 13$ & $60 \pm 12$ & $0.5 \pm 0.4$ \\
$\begin{array}{c}\text { Normal Controls } \\
(n=10)\end{array}$ & $14 \pm 3$ & $49 \pm 13$ & $37 \pm 14$ & $19 \pm 8$ & $1.9 \pm 0.9$ \\
\hline
\end{tabular}

$\star$ Uveitis patients with elevated CD4 +/CD8 + ratios in BAL fluid. 
significantly. T-lymphocyte subsets were determined in these patients and showed that there were increased proportions of CD3 + cells and CD4 + cells with elevated $\mathrm{CD} 4+/ \mathrm{CD} 8+$ ratios in 10 patients $(5.1 \pm 2.8)$. Other 6 patients showed normal CD4 + /CD8 + ratios $(1.1 \pm 0.5)$. Thus, T-cell subsets in BAL fluids from these 10 patients were compatible with those of patients with active pulmonary sarcoidosis (CD4 +/CD8 + ratios; 7.9 \pm 4.0 ), but different from those of patients with hypersensitivity pneumonitis who showed decreased $\mathrm{CD} 4+/ \mathrm{CD} 8+$ ratios $(0.5 \pm 0.4)$ (Table 1$)$.

Histology and histochemistry of lung tissues: Transbronchial lung biopsy was performed in 10 uveitis patients who showed BAL T-lymphocytosis and increased $\mathrm{CD} 4+/ \mathrm{CD} 8+$ cell ratios. Noncaseating epithelioid cell granuloma was found in 4 patients, but other 6 patients showed normal lung

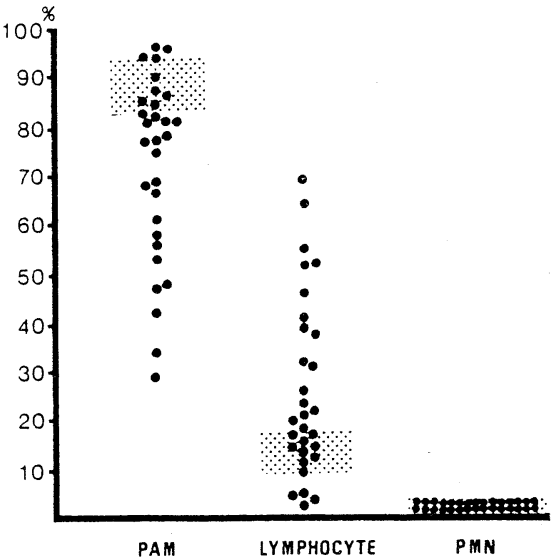

Fig. 1. Differential counts of bronchoalveolar lavage cells in uveitis patients

PAM: pulmonary alveolar macrophages, PMN: polymorphonuclear leukocytes, mormal range
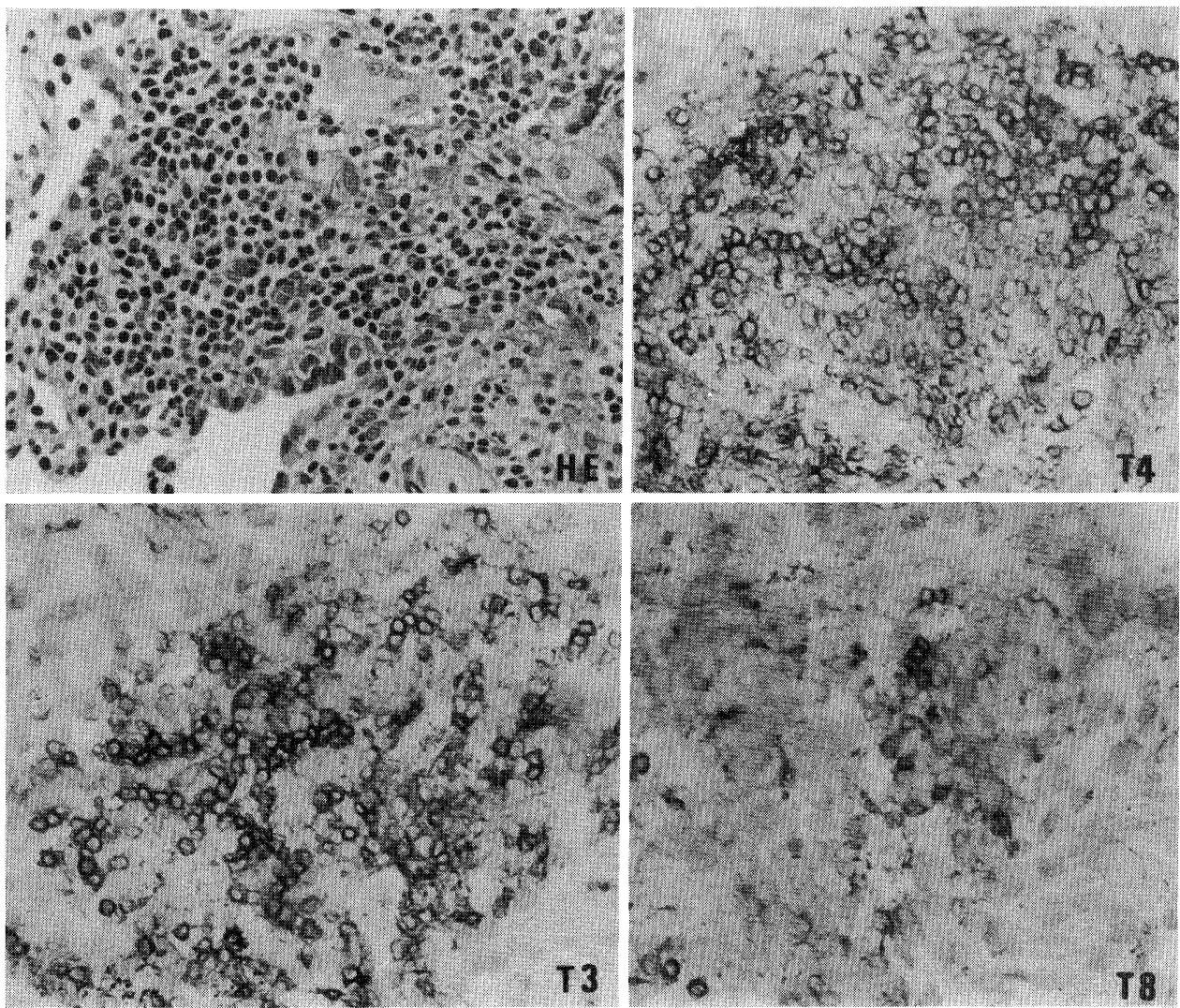

Fig. 2. T-cell subsets in the lung tissue obtained by transbronchial lung biopsy

HE: hematoxylin eosin staining, T3: CD3 + cells, T4: CD4 + cells, T8: CD8 + cells. Peroxidase-antiperoxidase technique. Original magnification $200 \times$. 
tissues. As shown in Figure 2, immunohistochemical studies of biopsied lung tissues showed many CD3 + cells and CD4 + cells with very few CD8 + cells in the granuloma.

Serum ACE levels: There was no increase of serum ACE levels in 15 of 16 uveitis patients who showed bronchoalveolar T-lymphocytosis (uveitis patients vs normal controls: $15.2 \pm 4.1$ vs $16.8 \pm$ $3.0 \mathrm{u} / \mathrm{l})$. Only one patient showed elevated serum ACE levels $(28.7 \mathrm{u} / \mathrm{l})$. In patients with pulmonary sarcoidosis, serum ACE levels were significantly elevated $(27.3 \pm 7.6 \mathrm{u} / \mathrm{l}, \mathrm{p}<0.01)$.

Serum levels of soluble IL-2 receptors: In normal controls, serum IL-2R levels were $286 \pm 49$ $\mathrm{U} / \mathrm{ml}$. Patients with pulmonary sarcoidosis and patients with hypersensitivity pneumonitis showed increased serum levels of soluble IL-2R (798 \pm 330 and $1133 \pm 66 \mathrm{U} / \mathrm{ml}$, respectively, $\mathrm{p}<0.01)$. In 10 uveitis patients with increased CD4 + /CD8 + ratios in BAL fluid, serum IL-2R levels were within normal limits $(240 \pm 35 \mathrm{U} / \mathrm{ml})$ (Figure 3$)$.

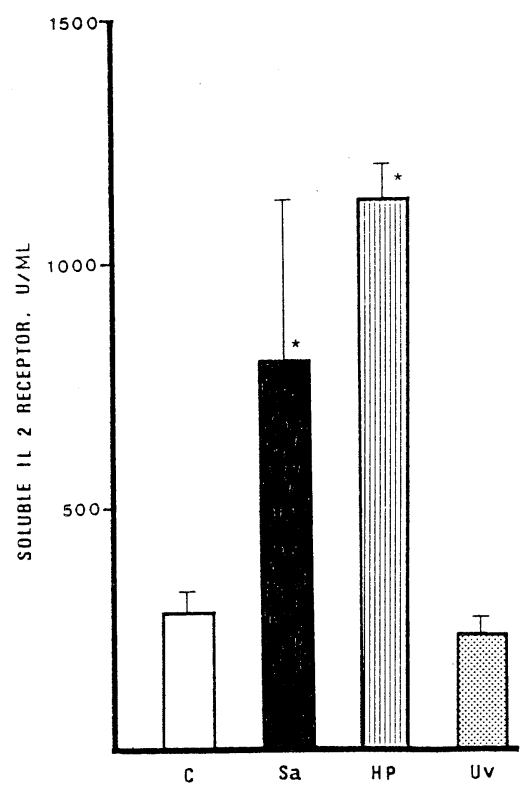

Fig. 3. Serum levels of soluble interleukin-2 receptors.

Sa: pulmonary sarcoidosis, HP: hypersensitivity pneumonitis, Uv: uveitis, C: normal controls, $* \mathrm{p}<0.01$

\section{DISCUSSION}

Although a diagnosis of sarcoidosis should be established on the basis of histological confirmation, the other examination such as BAL could make a diagnosis of sarcoidosis highly probable when confronted with uveitis patients with normal chest Xrays. The usefulness of BAL for detecting subclinical pulmonary involvement has been reported in patients with extrathoracic sarcoidosis (2), patients with Crohn's disease (3), patients with rheumatoid arthritis (4), and patients with HTLV-1-associated myelopathy (5). The present BAL study also demonstrated subclinical pulmonary involvement in $16(53.3 \%)$ of 30 uveitis patients who had a possible diagnosis of ocular sarcoidosis. Similarly, Wallaert and associates showed that there were increased percentages of BAL lymphocytes in $16(83.3 \%)$ of 18 patients with proved extrathoracic sarcoidosis and normal chest X-rays (2). However, there are some differences between the results of Wallaert et al. and ours. They showed normal percentages of CD3 + cells and normal CD4 + /CD8 + ratios in BAL fluid of patients with extrathoracic sarcoidosis. On the other hand, we found an increased proportion of $\mathrm{CD} 3+$ cells and elevated CD4 +/CD8 + ratios in 10 out of 16 uveitis patients. The discrepancy between the report of Wallaert et al. and ours is probably due to the difference of study populations because only 3 uveitis patients were included in their report (2). Bienfait and associates described BAL findings in 7 patients with suspected ocular sarcoidosis and normal chest X-rays, showing that 2 patients had BAL T-lymphocytosis with elevated $\mathrm{CD} 4+/ \mathrm{CD} 8+$ ratios (10).

In the present study, we confirmed histologically the pulmonary involvement of sarcoidosis in 4 patients, but not in 6 patients with T-lymphocytosis and elevated $\mathrm{CD} 4+/ \mathrm{CD} 8+$ ratios. BAL findings of T-cell subsets were consistent with immunohistochemical observations of T-cell subsets in the lung tissues obtained from 4 uveitis patients with noncaseating epithelioid cell granuloma. Previous reports have shown that the proportions of immune and inflammatory cells in BAL fluid reflect those in the alveolar structures $(2,11)$. Thus, pulmonary involvement of sarcoidosis are highly probable in 6 patients with BAL T-lymphocytosis 
and elevated CD4 $+/ \mathrm{CD} 8+$ ratios. However, we could not demonstrate in the present study whether other 6 patients with BAL T-lymphocytosis and normal $\mathrm{CD} 4+/ \mathrm{CD} 8+$ ratios had pulmonary involvement of sarcoidosis.

Serum ACE (S-ACE) activity has been reported to be a marker of disease activity in sarcoidosis (12-14). In the present study, only one patient with uveitis showed increased S-ACE activities, though patients with active pulmonary sarcoidosis (stage 1 and 2) showed significantly higher S-ACE activities. Wallaert and associates described that increased SACE activities were found in 3 of 18 patients with extrathoracic sarcoidosis (2). Bienfait and associates reported no correlation between BAL T-lymphocytosis and S-ACE levels in ocular sarcoidosis (10). These results suggest that S-ACE activities are not helpful in predicting the pulmonary involvement in patients with suspected ocular sarcoidosis and normal chest X-rays.

Recently, Lawrence and colleagues reported that serum levels of soluble IL-2R were elevated in active pulmonary sarcoidosis $(15,16)$. Our data confirmed the elevation of serum soluble IL-2R levels in pulmonary sarcoidosis as well as hypersensitivity pneumonitis. However, like S-ACE activities, serum levels of soluble IL-2R were not elevated in uveitis patients with subclinical pulmonary involvement.

In summary, T-lymphocytosis with increased $\mathrm{CD} 4+/ \mathrm{CD} 8+$ ratios in BAL fluids could be a good marker in predicting the pulmonary involvement of sarcoidosis in uveitis patients with normal chest Xrays. However, it remains to be determined whether respiratory tracts are the initial sites of involvement in uveitis patients.

ACKNOWLEDGEMENT: The writers thank Dr. Ryouichi Okamura, Professor of The Department of Ophthalmology, Kumamoto University Medical School for introducing patients with uveitis to our sarcoidosis clinic.

\section{REFERENCES}

1) Mitchell DN, Scadding JG: Sarcoidosis. Am Rev Respir Dis 110: 774, 1974.

2) Wallaert B, Ramon P, Fournier EC, et al: Activated alveolar macrophage and lymphocyte alveolitis in extrathoracic sarcoidosis without radiological mediastinopulmonary involvement. Ann NY Acad Sci 465: $201,1986$.

3) Wallaert B, Colombel JF, Tonnel AB, et al: Evidence of lymphocyte alveolitis in Crohn's disease. Chest 87: $363,1985$.

4) Garcia JGN, Parhami N, Killam D, et al: Bronchoalveolar lavage fluid evaluation in rheumatoid arthritis. Am Rev Respir Dis 133: 450, 1986.

5) Sugimoto $M$, Nakashima $H$, Watanabe $S$, et al: $T$ lymphocyte alveolitis in HTLV-I-associated myelopathy. Lancet ii: 1220, 1987.

6) Ando M, Sugimoto M, Nishi R, et al: Surface morphology and function of human pulmonary alveolar macrophages from smokers and nonsmokers. Thorax 39: $850,1984$.

7) Ando M, Yoshida K, Soda K, et al: Specific bronchoalveolar lavage $\operatorname{IgA}$ antibody in patients with summertype hypersensitivity pneumonitis induced by Trichosporon cutaneum. Am Rev Respir Dis 134: 177, 1986.

8) Kasahara Y, Ashihara Y: Colorimetry of angiotensinI converting enzyme activity in serum. Clin Chem 27: 1922, 1981.

9) Semenzato G, Foa R, Agonistini C, et al: High serum levels of soluble interleukin 2 receptor in patients with B chronic lymphocytic leukemia. Blood 70: 396, 1987.

10) Bienfait MF, Hoogsteden HC, Baarsma GS, et al: Diagnostic value of bronchoalveolar lavage in ocular sarcoidosis. Acta Ophthal 65: 745, 1987.

11) Hunninghake GW, Kawanami O, Ferrans VJ, et al: Characterization of the inflammatory and immune effector cells in the lung parenchyma of patients with interstitial lung disease. Am Rev Respir Dis 123: 407, 1981.

12) Lieberman J: Elevation of serum angiotensin-converting enzyme (ACE) level in sarcoidosis. Am J Med 59; 365, 1975.

13) DeRemee RA, Rohrbach MS: Serum angiotensinconverting enzyme activity in evaluating the clinical course of sarcoidosis. Ann Intern Med 92: 361, 1980.

14) Rohatgi PK, Ryan JW, Lindeman P: Value of serial measurement of serum angiotensin converting enzyme in the management of sarcoidosis. Am J Med 70: 44, 1981.

15) Lawrence EC, Berger MB, Brousseau KP, et al: Elevated serum levels of soluble interleukin 2 receptors in active pulmonary sarcoidosis: Relative specificity and association with hypercalcemia. Sarcoidosis 4: 87, 1987.

16) Lawrence EC, Brousseau KP, Berger MB, et al: Elevated concentrations of soluble interleukin-2 receptors in serum samples and bronchoalveolar lavage fluids in active sarcoidosis. Am Rev Respir Dis 137: 759, 1988. 